\title{
Single prolonged stress alters neural activation in the periacqueductal gray and midline thalamic nuclei during emotional learning and memory
}

\author{
Rebecca Della Valle, Negin Mohammadmirzaei, and Dayan Knox \\ Department of Psychological and Brain Sciences, University of Delaware, Newark, Delaware 19716, USA
}

\begin{abstract}
Clinical and preclinical studies that have examined the neurobiology of persistent fear memory in posttraumatic stress disorder (PTSD) have focused on the medial prefrontal cortex, hippocampus, and amygdala. Sensory systems, the periaqueductal gray (PAG), and midline thalamic nuclei have been implicated in fear and extinction memory, but whether neural activity in these substrates is sensitive to traumatic stress (at baseline or during emotional learning and memory) remains unexplored. To address this, we used the single prolonged stress (SPS) model of traumatic stress. SPS and control rats were either subjected to fear conditioning (CS-fear) or presented with CSs alone (CS-only) during fear conditioning. All rats were then subjected to extinction training and testing. A subset of rats were euthanized after each behavioral stage and c-Fos and c-Jun used to measure neural activation in all substrates. SPS lowered c-Jun levels in the dorsomedial and lateral PAG at baseline, but the elevated c-Jun expression in the PAG during emotional learning and memory. SPS also altered c-Fos expression during fear and extinction learning/memory in midline thalamic nuclei. These findings suggest changes in neural function in the PAG and midline thalamic nuclei could contribute to persistent fear memory induced by traumatic stress. Interestingly, SPS effects were also observed in animals that never learned fear or extinction (i.e., CS-only). This raises the possibility that traumatic stress could have broader effects on the psychological function that are dependent on the PAG and midline thalamic nuclei.
\end{abstract}

The single prolonged stress (SPS) model is an animal model of traumatic stress that mimics both the neuroendocrinological and behavioral symptoms of posttraumatic stress disorder (PTSD). Following exposure to SPS, which consists of 2-h restraint, 20-min forced swim, and exposure to diethyl ether, rodents display increases in arousal (Khan and Liberzon 2004; Kohda et al. 2007), abnormal sleep patterns (Vanderheyden et al. 2015), enhanced negative feedback of the hypothalamic-pituitary-adrenal (HPA) axis, up-regulated glucocorticoid receptor (GR) expression (Liberzon et al. 1997, 1999b; Knox et al. 2012b; Ganon-Elazar and Akirav 2013; George et al. 2015), decreased excitation in the medial prefrontal cortex (mPFC) (Knox et al. 2010, 2016), changes in the function of norepinephrine systems in the brain (George et al. 2012) and fear learning that is resistant to extinction (i.e., persistent fear memory) (Yamamoto et al. 2008; Knox et al. 2012a,b, 2016; George et al. 2015). These effects replicate the characteristic neuroendocrinological and behavioral features of PTSD (American Psychiatric Association 1994; Yehuda et al. 1996, 2006; Bremner et al. 1999; Liberzon et al. 1999a; Rothbaum and Davis 2003; Shin et al. 2004; Liberzon and Sripada 2008; van Zuiden et al. 2011, 2013; Bowers and Ressler 2015), and validate the use of SPS as an appropriate model of PTSD in rodents (Armario et al. 2008; Bowers and Ressler 2015; Deslauriers et al. 2018).

Animal models are particularly useful for examining neurobiological processes that lead to specific PTSD symptoms (Armario et al. 2008; Bowers and Ressler 2015; Deslauriers et al. 2018). Previous studies that have identified neural substrates through which SPS exposure leads to persistent fear memory have focused on the mPFC, basolateral amygdala (BLA), and hippocampus (Kohda et al. 2007; Knox et al. 2010, 2012b, 2016, 2018; George

\section{Corresponding author: dknox@psych.udel.edu}

Article is online at http://www.learnmem.org/cgi/doi/10.1101/lm.050310.119. et al. 2014;). These substrates have been consistently implicated in the etiology of PTSD (Liberzon and Sripada 2008; Maren et al. 2013; Bowers and Ressler 2015; Badura-Brack et al. 2018; Butler et al. 2018).

Sensory systems, neural substrates that generate fear output responses, and nonrelay midline thalamic nuclei are also critically involved in emotional learning and memory. The medial geniculate nucleus (MGN) and auditory cortex (AUD) are critical for auditory sensory processing, but may facilitate fear memory formation (Weinberger 2011; Aizenberg and Geffen 2013; Grosso et al. 2015; Gruene et al. 2016). The PAG, which serves as an output region for fearful behavior (Maren 2001; Paré et al. 2004; Orsini and Maren 2012; Assareh et al. 2016; Deng et al. 2016), has been implicated in fear and extinction memory formation (Carrive et al. 1997; McNally et al. 2004; Johansen et al. 2010; Kim et al. 2013; Koutsikou et al. 2015; Watson et al. 2016). The PAG is also critical for pain processing (Behbehani 1995; Heinricher et al. 2009) and specifically pain processing during fear learning (Rea et al. 2011; Kincheski et al. 2012).

Nonrelay midline thalamic nuclei have been implicated in fear and extinction memory. Neurons in the paraventricular nucleus of the dorsal midline thalamus (PVT) synapse on somatostatinexpressing neurons in the central amygdala and are critical for fear memory (Do-Monte et al. 2015; Penzo et al. 2015). The rhomboid (Rh) nucleus shows increased c-Fos expression following fear extinction (Furlong et al. 2016). The Rh and the ventrally adjacent

2019 Della Valle et al. This article is distributed exclusively by Cold Spring Harbor Laboratory Press for the first 12 months after the full-issue publication date (see http://learnmem.cshlp.org/site/misc/terms.xhtml). After 12 months, it is available under a Creative Commons License (AttributionNonCommercial 4.0 International), as described at http://creativecommons. org/licenses/by-nc/4.0/. 
nucleus reunions (RE) are important for facilitating functional connectivity between the mPFC and hippocampus (Hallock et al. 2016; Maisson et al. 2018) and is specifically critical for retrieval of specific contextual information during fear conditioning (Ramanathan et al. 2018). The medial habenula (mHab) has been implicated in the regulation of fear behavior (Zhang et al. 2016).

The effects of traumatic stress on neural activation in the AUD, MGN, PAG, PVT, Rh, Re, and mHab during fear and extinction memory remain unexplored. To address this SPS and control rats were fear conditioned, then subjected to extinction training and testing (CS-fear). The second set of SPS and control rats were presented with CSs during fear conditioning in the absence of footshocks, then subjected to extinction training and testing (CS-only). We have previously shown that animals in the CS-fear group, but not CS-only group, form fear and extinction memory (Knox et al. 2016). After fear conditioning, extinction training, or extinction testing, subsets of rats were euthanized to assay c-Fos and c-Jun in the AUD, MGN, PAG, PVT, mHab, Rh, and Re. We used these two immediate early genes because they are sometimes differentially regulated during emotional learning and memory (Knox et al. 2016, 2018). We also assayed c-Fos and c-Jun levels in a third set of SPS and control rats after immediate removal from the housing colony to establish baseline c-Fos and c-Jun levels. The experimental design is illustrated in Figure 1.

\section{C-Fos and c-Jun expression}

Expression of c-Fos and c-Jun in brain regions are illustrated in Figure 2. c-Fos and c-Jun levels during all behavioral sessions were separately analyzed using a learning (baseline, CS-fear, CS-only) $\times$ stress (SPS vs. control) factor design or expressed relative to baseline levels (i.e., normalized) and analyzed using a stress $\times$ normalized learning (CS-fear vs. CS-only) factor design.

\section{MGN and AUD}

SPS had no effect on the expression of c-Fos or c-Jun at baseline ( $P$ 's $>0.05$ ). Both the MGN and AUD showed significant differences in c-Fos expression during fear conditioning. There was a significant main effect of learning for signal activity in the MGN $\left(F_{(2,52)}=\right.$ 4.413, $P=0.017)$ and AUD $\left(F_{(2,52)}=4.526, P=0.015\right)$ as well as normalized activity $\left(\mathrm{MGN}: F_{(1,28)}=4.906, P=0.035\right.$; AUD: $F_{(1,28)}=$ $6.009, P=0.021)$. Rats in the CS-fear group had significantly higher c-Fos expression than animals in the CS-only group (Fig. 3A). There was no significant effect of stress on c-Fos expression during fear conditioning or significant effects of stress and/or learning on c-Fos expression in the AUD and MGN during extinction training and testing $\left(P^{\prime} \mathrm{s}>0.05\right)$. There were also no significant effects of stress and/or learning on c-Jun expression ( $P$ 's $>0.05$, Fig. 3B).

\section{Periaqueductal gray}

SPS had no effect on c-Fos expression at baseline in any PAG region ( $P$ 's $>0.05)$, but decreased c-Jun expression in the dorsomedial PAG $(\mathrm{dmPAG})\left(t_{(25)}=2.21, P=0.036\right)$. Also, c-Jun signal values were lower in the IPAG of SPS rats, which was suggested by a $t$-test comparison that approached significance $\left(t_{(25)}=1.99, P=0.057\right)$.

In all regions of the PAG, c-Fos expression was elevated in the CS-fear group during fear conditioning. These effects were revealed by significant main effects of learning for c-Fos signal values in the $\operatorname{vPAG}\left(F_{(2,53)}=7.153, P=0.002\right)$, dmPAG $\left(F_{(2,55)}=5.788, P=0.005\right)$, and $\operatorname{lPAG}\left(F_{(2,55)}=6.82, P=0.002\right)$. Post-hoc comparisons for CS-fear vs. baseline (vPAG: $t_{(41)}=3.265, P=0.006$; dmPAG: $t_{(42)}=$ 3.355, $P=0.006$; IPAG: $\left.t_{(42)}=3.987, P<0.001\right)$ also supported this assertion. These post-hoc comparisons were not significant for CS-only vs. CS-baseline ( $\left.P^{\prime} \mathrm{s}>0.05\right)$. Analysis of c-Fos normalized values resulted in a significant effect of learning $\left(F_{(1,28)}=\right.$ 7.157, $P=0.012$ ) with c-Fos normalized values being higher for the CS-fear vs. CS-only group. It should be noted that in the vPAG, significant effects of learning were driven largely by enhancements in c-Fos values in the SPS rats in the CS-fear condition. Enhanced c-Fos signal $\left(F_{(2,47)}=4.768, P=0.013\right)$ and normalized $\left(F_{(1,29)}=4.489, P=0.043\right)$ values in the dmPAG during extinction training was revealed by significant main effects of learning. Enhanced c-Fos signal values $\left(F_{(2,55)}=5.274, P=0.008\right)$ were also observed in the IPAG during extinction training. These two effects represented enhanced c-Fos signal values in the CS-fear group vs. baseline (dmPAG: $t_{(41)}=4.144, P<0.001$; IPAG: $t_{(41)}=3.638, P=$ $0.002)$, but not CS-only vs. baseline $\left(P^{\prime} \mathrm{s}>0.05\right)$. C-Fos values in the vPAG were equivalent among all groups during extinction training $\left(P^{\prime} \mathrm{s}>0.05\right)$. During extinction testing, c-Fos values were equivalent among all groups in all PAG regions $\left(P^{\prime} \mathrm{s}>0.05\right)$. These results are illustrated in Figure 4A.

Analysis of signal values for c-Jun expression in the vPAG and IPAG did not reveal significant comparisons for fear conditioning $\left(P^{\prime} \mathrm{s}>0.05\right)$. There was a stress $\times$ learning interaction that approached significance $\left(F_{(2,54)}=2.864, P=0.066\right)$ for c-Jun signal values in the dmPAG. This reflected the tendency for c-Jun expression to increase (relative to baseline) in SPS rats, but decrease (relative to baseline) in control rats. Consistent with this interpretation,

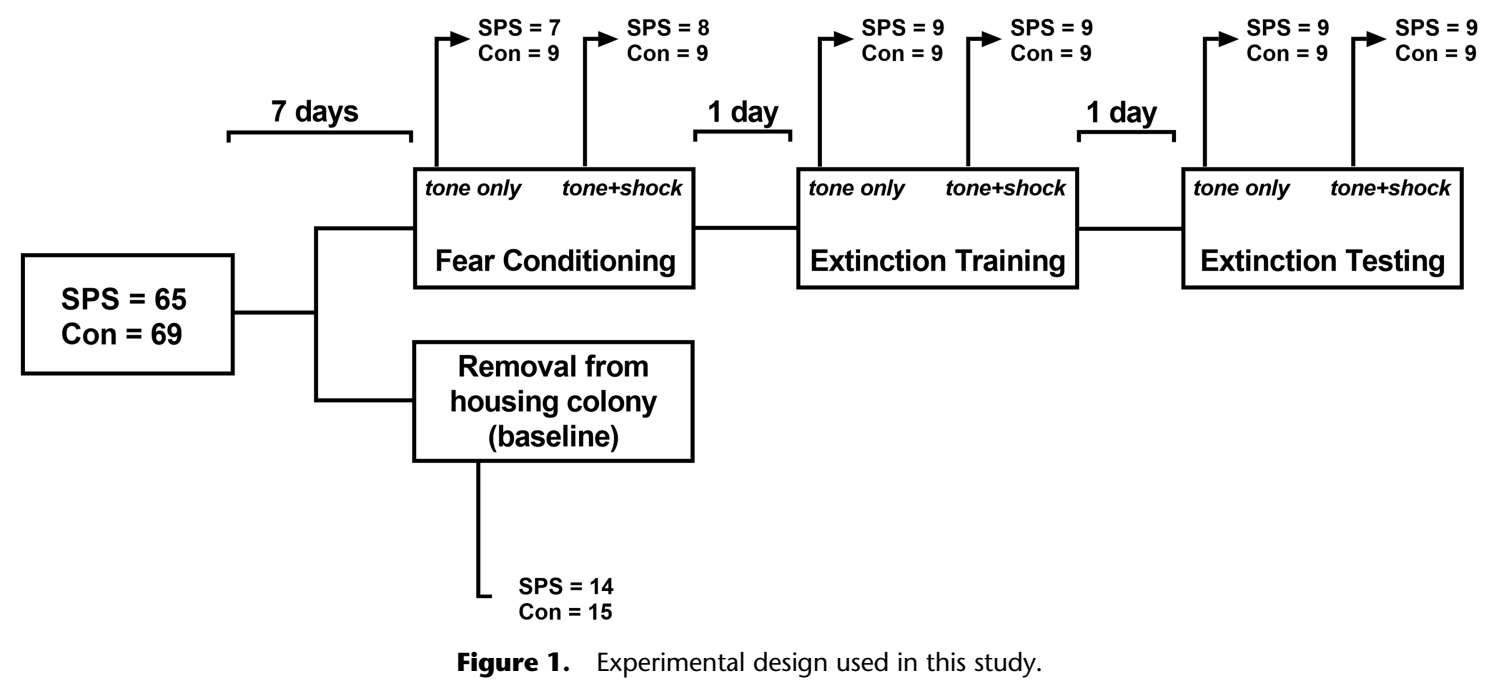


A
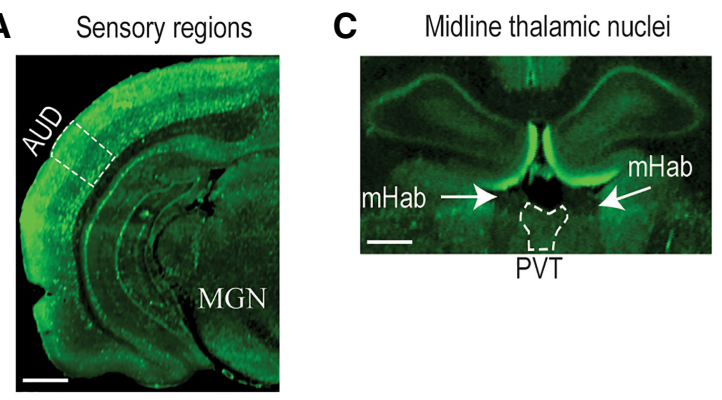

B Periaqueductal gray

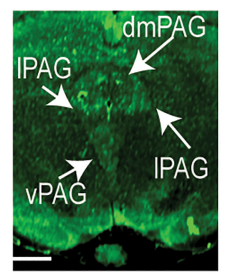

Figure 2. Representative high resolution $(21 \mu \mathrm{m})$ scanned images of brain regions obtained using the Licor Odyssey scanner. Eight hundred nanaometers near-infrared fluorescence was used to measure c-Fos and c-Jun levels in all brain regions. ( $A$ ) Sensory regions showing the AUD and MGN. (B) The PAG was divided into dorsal PAG (dPAG), lateral PAG (IPAG), and ventral PAG (vPAG). (C) Midline thalamic nuclei analyzed in this study. (left) $\mathrm{mHab}$ and PVT. (right) Rh nucleus and nucleus reuniens (RE). White horizontal line denotes $1 \mathrm{~mm}$ distance.

analysis of normalized c-Jun expression was higher in the dmPAG of SPS rats during fear conditioning (main effect of stress: $F_{(1,29)}=$ $3.056, P=0.04)$. Analysis of c-Jun signal values for extinction training did not reveal significant effects in the dmPAG $\left(P^{\prime} \mathrm{s}>0.05\right)$, but c-Jun normalized values were enhanced in SPS rats (main effect of

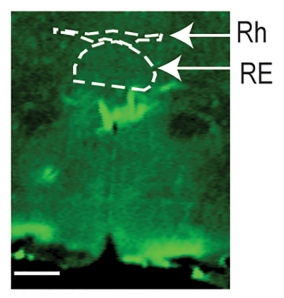

stress: $\left.F_{(1,31)}=5.561, P=0.025\right)$. SPS also enhanced signal (stress $\times$ learning interaction: $\left.F_{(2,56)}=3.422, P=0.04\right)$ and normalized (main effect of stress: $F_{(1,31)}=11.959$, $P=0.002)$ dmPAG c-Jun values during extinction testing. SPS enhanced normalized c-Jun values during extinction training (main effect of stress: $F_{(1,31)}=14.269$, $P=0.001$ ) and testing (main effect of stress: $\left.F_{(1,31)}=12.762, P=0.001\right)$ in the vPAG and during extinction testing in the IPAG (main effect of stress: $F_{(1,31)}=$ $14.168, P=0.001)$. Notably, all of these stress effects were observed in SPS rats in the CS-fear and CS-only conditions. These results are illustrated in Figure 4B.

\section{Thalamic nuclei}

Baseline levels of c-Fos and c-Jun were equivalent in all midthalamic regions between SPS and control rats $\left(P^{\prime} \mathrm{s}>0.05\right)$. During fear conditioning, there were no significant effects of stress and learning on c-Fos signal values $\left(P^{\prime} \mathrm{s}>0.05\right)$. In the Rh, SPS decreased c-Fos normalized values during fear conditioning (main effect of stress: $\left.F_{(1,29)}=10.889, P=0.003\right)$. Significant one-sample $t$-test for c-Fos normalized values in the PVT $\left(t_{(32)}=3.259, P=0.003\right)$, mHab $\left(t_{(32)}=3.628, P=0.001\right)$, and RE $\left(t_{(32)}=3.257, P=0.003\right)$ reflected enhanced c-Fos levels relative to baseline in all rats. During extinction training, c-Fos signal values were lower in the CS-fear and CS-only conditions, relative to baseline, in the PVT (main
A
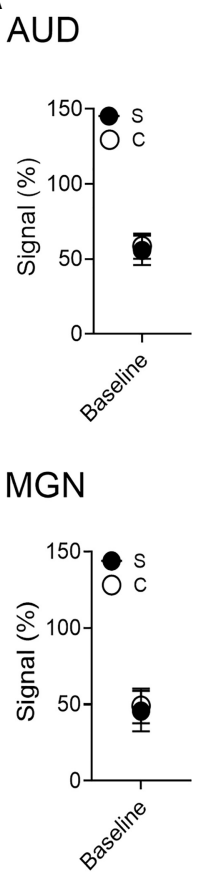

\section{C-Fos}
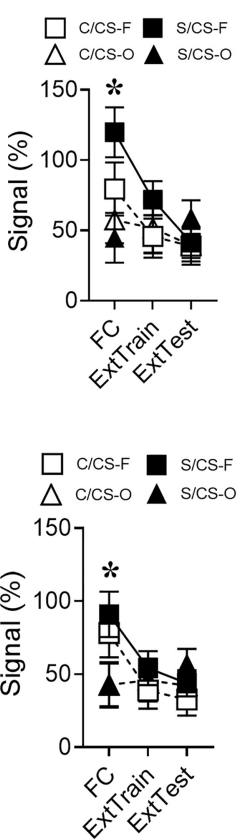
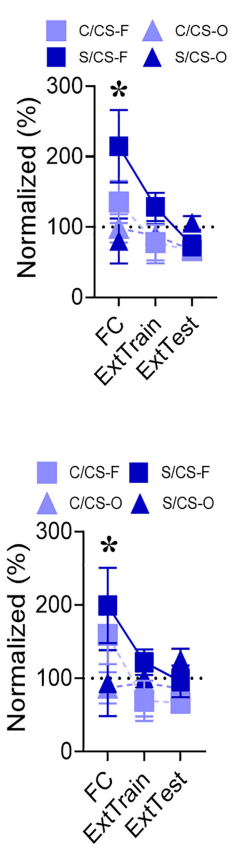

B

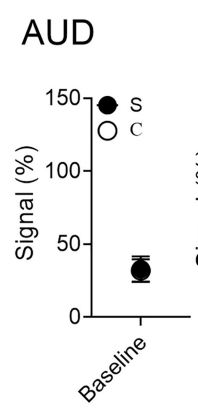

C-Jun
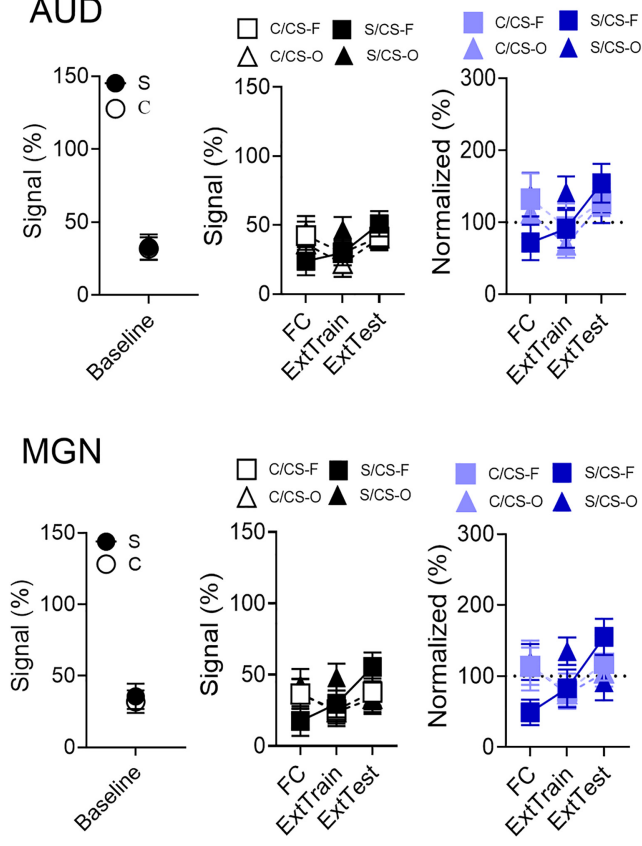

Figure 3. Effect of SPS and emotional learning/memory on c-Fos and c-Jun levels in the AUD and MGN. (A) During fear conditioning (FC) c-Fos levels were elevated in the AUD and MGN in all animals in the CS-fear (CS-F) group relative to the CS-only (CS-O). These effects were equivalent in SPS (S) and control (C) rats. Neither stress nor learning had any effect on c-Fos expression during extinction training (ExtTrain) or extinction testing (ExtTest). (B) Neither stress nor learning had any effect on c-Jun expression in the AUD and MGN. $\left(^{*}\right) P<0.05$. 
A

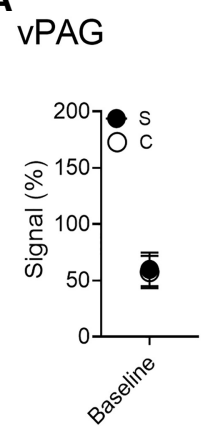

dmPAG

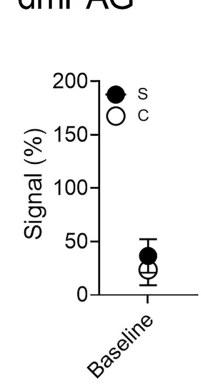

IPAG

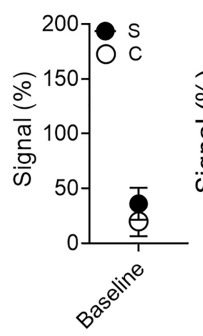

C-Fos
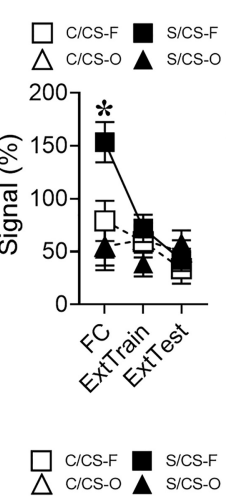

$$
\triangle \text { C/CS-O } \boldsymbol{\Delta} \text { S/CS-O }
$$

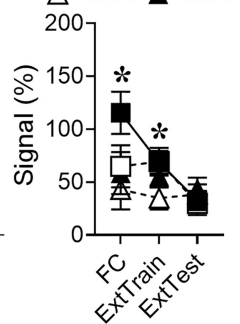

$$
\square \text { CS-F } \square \text { S/CS-F }
$$

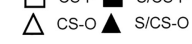

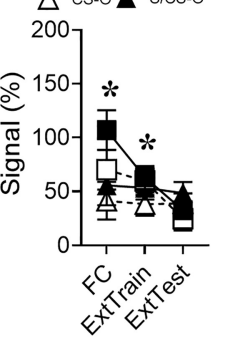
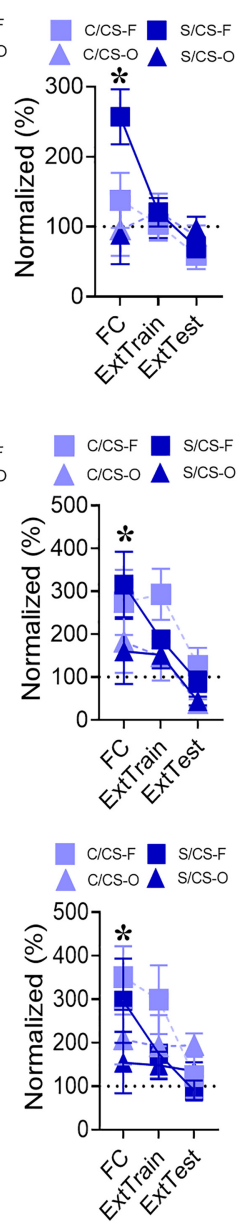

B
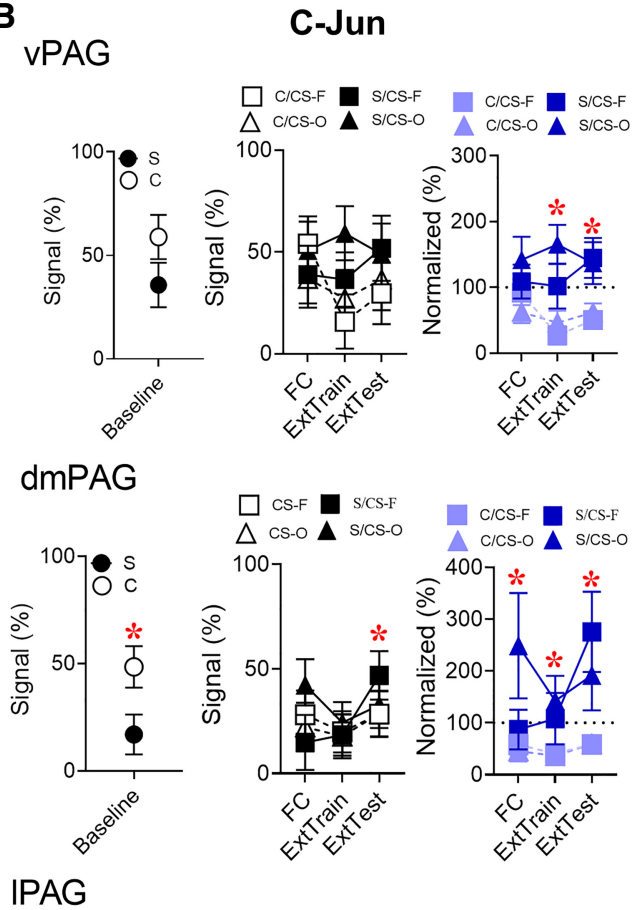

IPAG

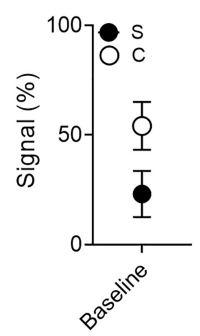

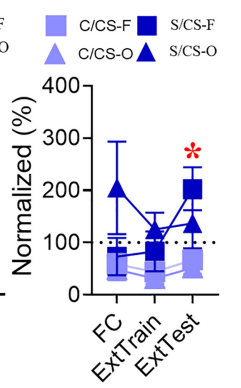

Figure 4. Effect of SPS and emotional learning/memory on c-Fos and c-Jun levels in the PAG. (A) FC enhanced c-Fos expression in all PAG regions and enhanced c-Fos signal values during extinction training in the dmPAG and IPAG. SPS had no effect on c-Fos expression in any PAG region. (B) SPS decreased basal levels of c-Jun in the dmPAG and possibly decreased basal levels of c-Jun in the IPAG (effect approached significance). SPS also enhanced c-Jun expression (relative to controls) during ExtTrain and ExtTest in the vPAG, during all behavioral sessions in the dmPAG, and during ExtTest in the IPAG. Black * represents the effects of learning while red * represents the effects of stress. All * are for statistical comparisons at $P<0.05$ criterion.

effect of learning: $\left.F_{(2,57)}=7.607, P=0.001\right)$, mHab (main effect of learning: $F_{(2,57)}=7.937, P=0.001$ ), and RE (main effect of learning: $\left.F_{(2,61)}=9.174, P=0.001\right)$.

Analysis of c-Fos normalized values in the PVT $\left(F_{(1,32)}=4.446\right.$, $P=0.043)$, mHab $\left(F_{(1,32)}=6.891, P=0.0103\right)$, and $\operatorname{RE~}\left(F_{(1,31)}=\right.$ $5.212, P=0.029)$ revealed main effects of stress during extinction training. This reflected the enhancements in c-Fos normalized values in SPS rats (in the CS-fear and CS-only conditions) relative to control rats. In the Rh, SPS decreased c-Fos normalized values during extinction training (main effect of stress: $F_{(1,31)}=16.340, P<$ 0.001). During extinction testing there was a significant effect of learning with c-fos signal values being lower in the CS-fear and CS-only groups, relative to baseline, in the PVT $\left(F_{(2,56)}=5.16, P=\right.$ $0.009)$, mHab $\left(F_{(2,56)}=4.476, P=0.016\right)$, and RE $\left(F_{(2,55)}=5.17, P=\right.$ $0.009)$. SPS decreased c-Fos normalized values in the Rh during extinction testing (main effect of stress: $F_{(1,31)}=46.986$ ). There was also the main effect of learning during extinction testing for c-Fos normalized values in the $\mathrm{Rh}\left(F_{(1,32)}=4.768, P=0.037\right)$. This reflected a decrease in c-Fos normalized values in the CS-fear relative to the CS-only group, but this effect was primarily driven by decreased c-Fos normalized values in SPS rats. These results are illustrated in Figure 5A.
During fear conditioning c-Jun signal values decreased in the $\mathrm{PV}, \mathrm{mHab}, \mathrm{RE}$, and $\mathrm{Rh}$ in the CS-fear and CS-only conditions relative to baseline. This was evidenced by main effects of learning that approached significance for c-Jun signal values in the mHab $\left(F_{(2,54)}=3.135, \quad P=0.056\right)$, main effects of learning for c-Jun signal values in the $\operatorname{RE}\left(F_{(2,54)}=3.279, P=0.045\right)$ and $\operatorname{Rh}\left(F_{(2,54)}=\right.$ $3.279, P=0.045)$, and significant one-sample $t$-tests for normalized c-Jun values in all midline thalamic regions (PV: $t_{(31)}=-13.116, P<$ 0.001, mHab: $t_{(31)}=-15.002, P<0.001$, RE: $t_{(31)}=-21.449, P<$ 0.001 , Rh: $\left.t_{(31)}=-21.728, P<0.001\right)$. Lowered c-Jun expression in midline thalamic brain regions was also observed during extinction training. C-Jun signal values in the mHab (learning: $F_{(2,57)}=3.003$, $P=0.058$ ), RE (learning: $F_{(2,57)}=3.135, P=0.051$ ), and Rh (learning: $\left.F_{(2,54)}=3.142, P=0.051\right)$ were lower than baseline, though all effects of learning approached significance. One-sample $t$-tests for normalized c-Jun values in all midline thalamic brain regions during extinction training were significant $\left(\mathrm{PV}: t_{(34)}=-7864, P<\right.$ 0.001 , mHab: $t_{(34)}=-6.219, P<0.001$, RE: $t_{(34)}=-8.546, P<0.001$, Rh: $\left.t_{(34)}=-8.454, P<0.001\right)$, which reflected lowered c-Jun values during extinction training. There were no significant effects for c-Jun signal values observed during extinction testing. Results for expression of c-Jun in thalamic nuclei are shown in Figure 5B. 
A

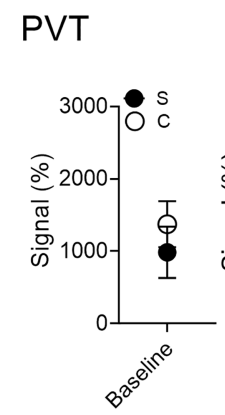

$\mathrm{mHab}$

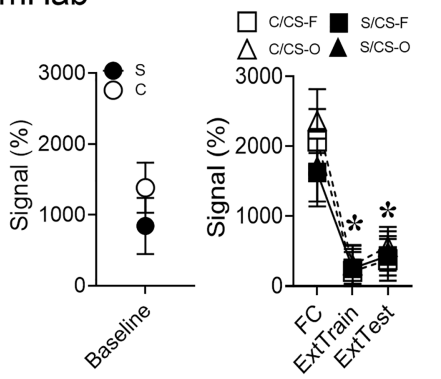

RE
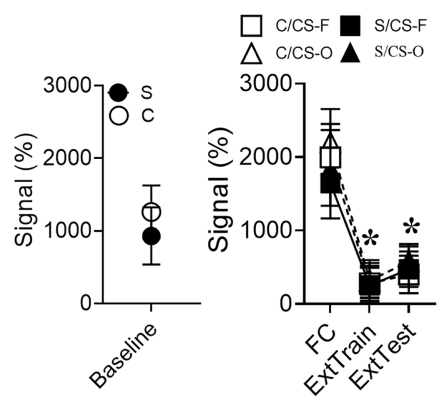

$\mathrm{Rh}$
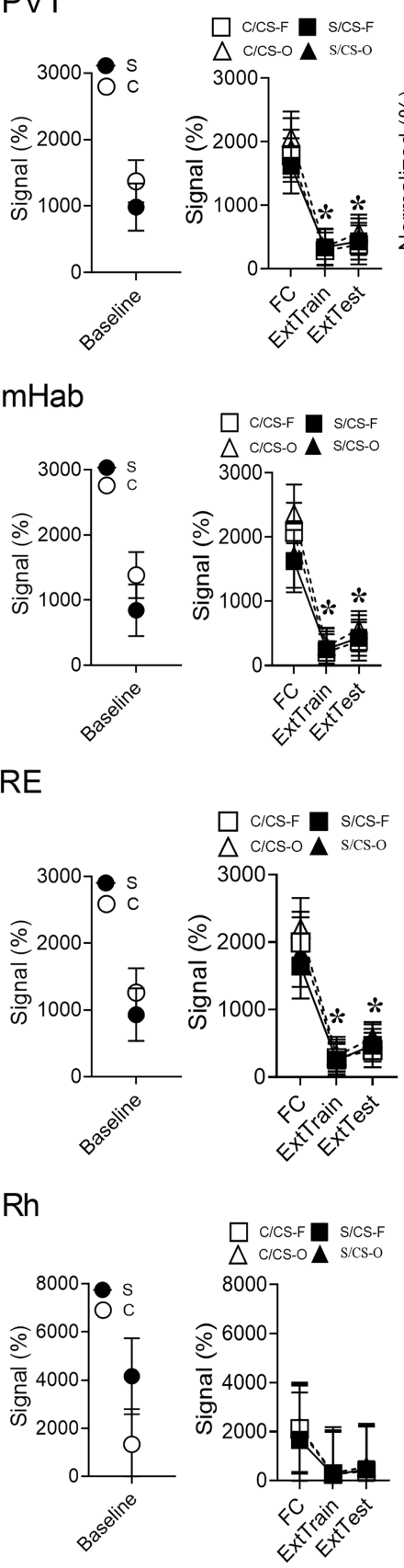

C-Fos
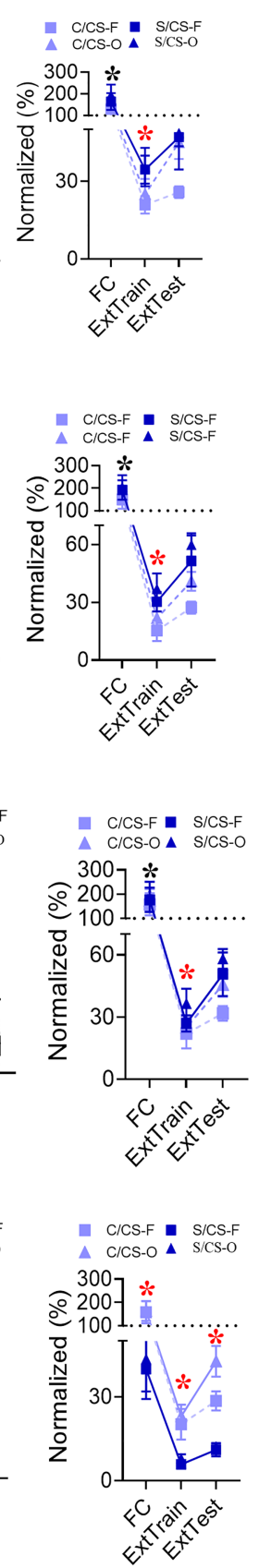

B

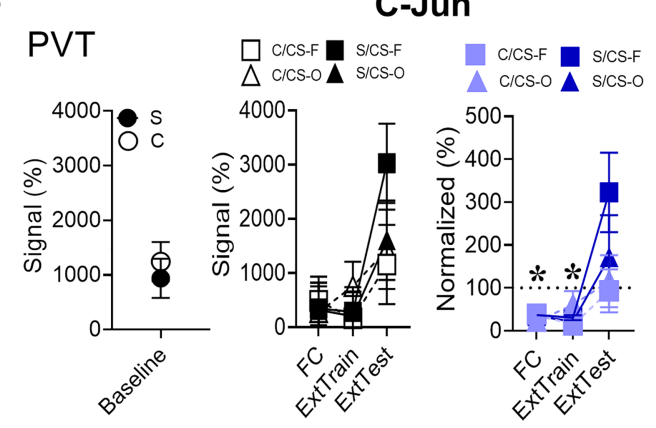

$\mathrm{mHab}$
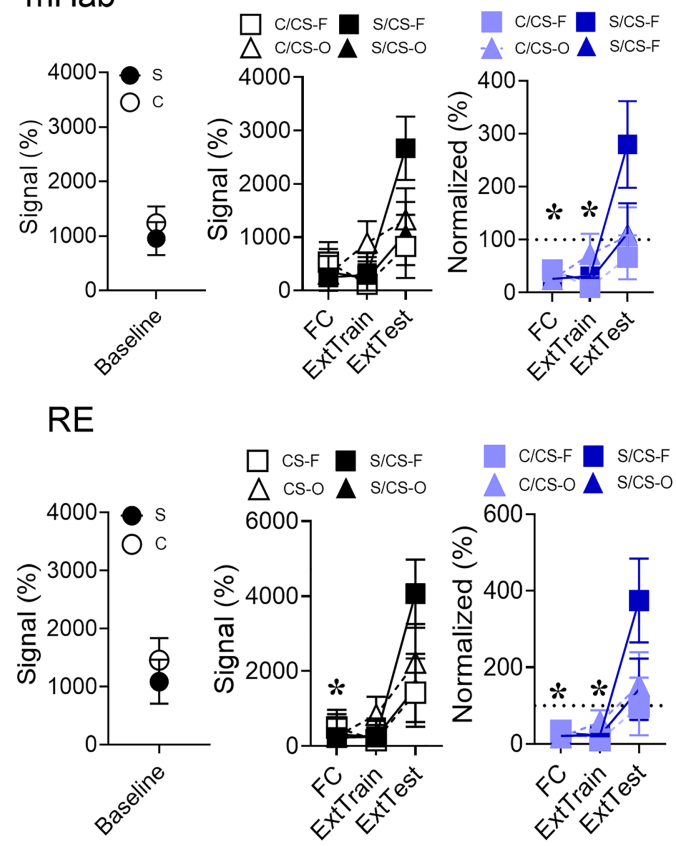

$\mathrm{Rh}$
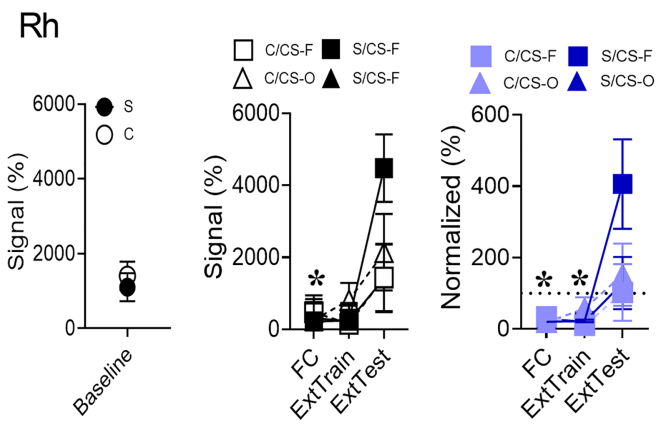

Figure 5. Effect of SPS and emotional learning/memory on c-Fos and c-Jun levels in midline thalamic regions. (A) During FC c-Fos levels were enhanced in all midline thalamic regions, then decreased below baseline levels during ExtTrain and ExtTest. During ExtTrain this decrease was lower in SPS rats in comparison to control rats in the PVT, $\mathrm{mHab}$, and RE. SPS lowered normalized c-Fos levels in the Rh during FC, ExtTrain, and ExtTest. Y-axes for normalized c-Fos values are split to visualize stress effects during ExtTrain. (B) During FC and ExtTrain, C-Jun levels decreased in all midline thalamic regions relative to baseline. SPS had no effect on c-Jun levels in any midline thalamic region. Black * represent the effects of learning while red * represent the effects of stress. All * are for statistical comparisons at $P<0.05$ criterion.

\section{Discussion}

The goal of this study was to determine if SPS alters neural activation in the PAG and midline thalamic nuclei during emotional learning and memory. SPS induced changes in neural activation (measured using c-Fos and c-Jun) in the PAG at baseline and during fear conditioning, extinction training, and extinction testing. SPS also induced changes in neural activation in midline thalamic nuclei during fear conditioning, extinction training, and extinction testing. These findings suggest that SPS-induced changes in neural activation in the PAG and midline thalamic nuclei could contribute to persistent fear memory in the SPS model. Previous studies have observed that changes in neural activation in the MPFC, BLA, and hippocampus (dorsal and ventral) may contribute to 
persistent fear memory in the SPS model (Knox et al. 2016, 2018). Together, these findings suggest that persistent fear memory in the SPS model may be due to changes in neural activation throughout multiple nodes within the fear circuit that either strengthen fear memory or bias fear memory expression.

In the vPAG there was an enhancement in c-Fos levels in the CS-fear group, with the largest effect being observed in the SPS/ CS-fear group. This could be related to fear memory formation, but it could also be due to the processing of pain with footshock presentation. SPS effects in the dmPAG and IPAG, as well as midline thalamic nuclei during emotional learning and memory, were present in both CS-fear and CS-only groups. The CS-only group never learned fear and thus never learned extinction. Similar effects have been observed in the mPFC, BLA, and hippocampus (Knox et al. 2016, 2018). These particular results suggest two things. (1) SPS-induced changes in neural activation in the PAG and midline thalamic nuclei occur when there is evoked neural activation in these substrates; not just during emotional learning and memory. (2) SPS could induce changes in psychological function that depend on the PAG (e.g., pain processing) or midline thalamic nuclei (e.g., spatial working memory). Previous studies support this hypothesis as SPS alters pain tolerance and disrupts spatial memory in the Morris Water Maze (Imanaka et al. 2006; Wang et al. 2010).

In all midline thalamic nuclei, there was a decrease in c-Fos expression after fear conditioning or initial CS exposure. This suggests that these midline thalamic nuclei respond to novelty and decrease neural activation with repeated stimulus presentation. In the Re, PVT, and mHab this decrease in responsivity after fear conditioning or initial CS exposure was inhibited in SPS animals during extinction training. Given that habituation and extinction learning/memory share common neurobiological processes (Furlong et al. 2016; Knox et al. 2016, 2018), this decrease in habituation observed in SPS rats could be relevant to persistent fear memory in the SPS model. Further research is needed to examine this possibility.

Learning-specific effects were observed in sensory brain regions and in the PAG, where animals in the CS-fear group showed enhance neural activation relative to baseline and the CS-only group during fear conditioning (see Results). These findings are consistent with the role of these brain regions in facilitating fear memory (see Introduction). However, c-Jun expression never followed changes in c-Fos expression with no c-Jun up-regulation in sensory brain regions, no learning-specific changes in c-Jun expression in the PAG, and down-regulation of c-Jun expression in midline thalamic regions with fear conditioning and extinction training. These findings replicate previous findings that suggest c-Fos and c-Jun are not regulated in an equivalent manner with evoked neural activity (Schneider et al. 1992; Eferl and Wagner 2003; Teather et al. 2005; Madsen et al. 2006; Windak et al. 2013; Knox et al. 2016, 2018). This differential response of these two immediate early genes could represent different populations of neurons in respective brain regions or specific activity in molecular pathways within the same neuron. Further research examining these possibilities is needed as evoked c-Fos and c-Jun expression in different brain regions may be used to monitor more specific activity in neurons.

\section{The role of PAG subregions and midline thalamic nuclei in emotional memory}

Both the PAG and midline thalamic nuclei have roles to play in emotional memory which further reinforces the possibility that SPS could act through these substrates to enhance persistent fear memory. The dmPAG is critical for fear memory (Carrive et al. 1997; Liberzon et al. 1999a; Maren 2001; McNally et al. 2004;
Paré et al. 2004; Johansen et al. 2010; Orsini and Maren 2012; Kim et al. 2013; Assareh et al. 2016; Watson et al. 2016; Butler et al. 2018). A previous study has observed that c-Fos is elevated in the vPAG during fear conditioning (Carrive et al. 1997) and the IPAG is involved in the generation and inhibition of fear responses (Assareh et al. 2016). Activation of the ventrolateral PAG has been previously shown to be critical for extinction memory (McNally et al. 2004; Assareh et al. 2016).

The $\mathrm{Rh}$ and Re, due to its interconnectivity with both the mPFC and hippocampus, is critical for spatial working memory (Hallock et al. 2016) as well as contextual fear memory (Ramanathan et al. 2018). Extinction memory recall is heavily dependent on contextual feature processing during extinction training and testing (Bouton et al. 2006; Maren et al. 2013). Thus the Rh and Re could affect either formation or expression of extinction memory by altering contextual processing during extinction learning and memory recall. The PVT and $\mathrm{mHab}$ are critical for fear memory with the PVT being critical for the consolidation of longterm fear memory (Do-Monte et al. 2015; Zhang et al. 2016) while input from the $\mathrm{mHab}$ to the interpeduncular nucleus being critical for the inhibition of fear memory (Zhang et al. 2016).

There are a number of mechanisms via which SPS-induced changes in PAG and midline thalamic neurobiology could contribute to persistent fear memory in the SPS model. Further research is needed to identify exact mechanisms.

\section{Conclusions}

The data presented here suggest that SPS, a well-validated rodent model of PTSD, has significant effects on basal and evoked neural activation in the PAG and neural activation in midline thalamic nuclei. SPS decreased basal neural activation in the dmPAG and IPAG, enhanced evoked neural activation in the dmPAG, IPAG, and vPAG, and had a consistent decrease in evoked Rh neural activation. SPS also consistently disrupted habituation in the PVT, Re, and mHab during extinction training. When taken together with previous findings (Kohda et al. 2007; Knox et al. 2016, 2018) our results raise the possibility that persistent fear induced by traumatic stress may represent the synergistic action of neural activation across multiple nodes within the fear circuit, which could explain why persistent fear memory that accompanies traumatic stress exposure can be difficult to treat. All SPS effects during emotional learning and memory were not specific to emotional learning and memory. This suggests that SPS induced changes in neural activation in the PAG and midline thalamic nuclei could disrupt psychological function that are dependent on these neural substrates.

\section{Materials and Methods}

\section{Animals}

For this study, 136 adult male Sprague Dawley rats (150 g upon arrival) were obtained from Charles River Inc. This strain and sex of rat was used because SPS-induced changes in emotional memory has been extensively characterized in this strain and sex of rat (Imanaka et al. 2006; Iwamoto et al. 2007; Kohda et al. 2007; Knox et al. 2012a,b, 2016; George et al. 2014; Noble et al. 2017). Rats were kept on a 12-h light/dark cycle. Prior to SPS exposure, all rats were pair housed and had ad libitum access to food initially, but were then restricted to the manufacturer's recommended diet (LabDiet) of $23 \mathrm{~g}$ per day. Access to water was ad libitum for the duration of the study. Experimental manipulations commenced after rats had been in the housing colony for at least $5 \mathrm{~d}$. All experimental procedures were performed in the animals' light cycle and all behavioral tests were conducted between 9:00 a.m. and 2:00 p.m. All experiments were approved by the University of Delaware Institutional Animal Care and Use Committee following guidelines established by the National Institutes of Health (NIH). 


\section{SPS and behavioral procedures}

Rats were assigned at random to either the SPS or control group. SPS was conducted as previously described (Liberzon et al. 1997; Knox et al. 2010) and consisted of $2 \mathrm{~h}$ of restraint, $20 \mathrm{~min}$ of forced swim, and ether exposure until general anesthesia was induced. Rats assigned to the control group were removed from the colony room and placed in a novel room for the duration of SPS. After SPS, all rats were returned to the housing colony and singly housed for a poststress incubation period of $7 \mathrm{~d}$ prior to behavioral testing. This incubation period as well as the combination of restraint, forced swim, and ether exposure is necessary to observe effects in the SPS model (Liberzon et al. 1997, 1999a; Knox et al. 2012a,b).

SPS and control rats were then divided into three further groups based on their behavioral treatment. A baseline group used to establish baseline levels of c-Fos and c-Jun expression, was removed from the housing colony and immediately euthanized. The CS-fear group was subjected to auditory fear conditioning, then extinction training and testing (see below). The CS-only group was presented with CSs in the absence of footshock during fear conditioning, then presented with CSs in an identical manner to animals in the CS-fear group undergoing extinction training and testing. We used the CS-only treatment in order to control for changes in c-Fos and c-Jun expression driven by habituation to a tone or a context. We have previously shown that conditioned freezing in the CS-only group is low throughout all behavioral sessions (Knox et al. 2016).

Fear conditioning was conducted in a distinct context (Context A) and consisted of five presentations of a $10 \mathrm{sec}$ auditory $\mathrm{CS}(2 \mathrm{kHz}, 80 \mathrm{~dB})$ coterminating with a $1 \mathrm{~mA}, 1 \mathrm{sec}$ footshock unconditioned stimulus (UCS). The CS-only group had CS presentations in the absence of footshocks. Extinction training in a novel context (Context B) commenced $1 \mathrm{~d}$ after fear conditioning and consisted of 30 unpaired CS presentations. Extinction testing, also in Context B, was conducted $1 \mathrm{~d}$ after extinction training and consisted of 10 unpaired CS presentations. Contexts A and B were created by manipulating multiple sensory cues, including house light color, contextual odor, and the identity of the experimenter (Knox et al. 2012a). All behavioral sessions consisted of a baseline period of $210 \mathrm{sec}$ and inter-stimulus intervals (ISIs) of $60 \mathrm{sec}$.

\section{c-Fos and c-Jun immunocytochemistry}

Rats were euthanized via rapid decapitation either after immediate removal from the housing colony (baseline group) or $60 \mathrm{~min}$ after the start of fear conditioning, extinction training, or extinction testing (CS-fear and CS-only groups). Brains were then extracted and flash frozen in chilled isopentane and stored in a $-80^{\circ} \mathrm{C}$ freezer until further processing. Brains were thawed to $-13^{\circ} \mathrm{C}$ in a cryostat (Leica CM1350) and $30 \mu \mathrm{m}$ coronal sections through the thalamus and PAG were mounted onto superfrost slides. Brain sections were then stored in $\mathrm{a}-80^{\circ} \mathrm{C}$ freezer until time of assay.

In order to perform c-Fos and c-Jun immunocytochemistry, sections were fixed in $4 \%$ paraformaldehyde in $0.2 \mathrm{M}$ phosphate buffered saline (PBS). Sections were then incubated in Triton $\mathrm{X}-100$, rinsed in $0.1 \mathrm{M}$ tris buffered saline (TBS) and incubated in $3 \%$ goat serum. Sections were rinsed again in TBS and incubated with either a rabbit polyclonal c-Fos (1:500) or c-Jun (1:1000) antibody (Santa Cruz Biotechnology, sc-52) in PBS overnight at $4^{\circ} \mathrm{C}$. Sections were then rinsed in TBS containing $0.01 \%$ Tween-20 (TBS-T). After this, sections were incubated in a solution consisting of TBS, $1.5 \%$ goat serum, $0.1 \%$ Triton $\mathrm{X}-100$, and goat anti-rabbit IgG antibody 800CW (Li-cor Biotechnology 926-32211) in a dilution of 1:2000 for $2 \mathrm{~h}$. Sections were rinsed in TBS-T, TBS, and then deionized water. Sections were then left to air-dry overnight.

\section{Data and statistical analysis}

We have previously validated the use of the $800 \mathrm{CW}$ secondary antibody to detect c-Fos and c-Jun using immunohistochemistry (e.g., see Knox et al. 2012b, 2018). Dried brain sections were scanned at $21 \mu \mathrm{m}$ resolution in the Odyssey scanner. Fluorescent activity in the PAG (with dorsal, lateral, and ventral regions sepa- rately scored), PVT, Rh, mHab, RE, MGN, and AUD was scored manually using ImageStudio software (Licor Inc.) and expressed as a percent change from activity in the corpus callosum. We refer to this as a signal activity. Signal activity from all brain regions in the baseline condition was subjected to $t$-test (SPS vs. control). Signal activity obtained from rats euthanized after fear conditioning, extinction training, and testing was analyzed using a stress $x$ learning separately for fear conditioning, extinction training, and extinction testing. The signal activity was also normalized with respect to baseline signal activity. For example, vPAG signal activity from an SPS rat in the CS-only condition was normalized relative to averaged vPAG signal activity of SPS rats in the baseline condition. We refer to this as a normalized activity. The normalized activity was constructed so that signal activity during fear conditioning, extinction training and testing that was equal to baseline signal activity would yield a normalized score of $100 \%$ (i.e., (signal activity/averaged baseline activity) $\times 100$ ). The normalized activity of c-Fos and c-Jun in all brain regions during fear conditioning, extinction training, and extinction testing were subjected to separate stress $\times$ normalized learning factor designs.

All statistical tests were performed in IBM SPSS statistics 24 . For all factor designs, main effects and interactions were analyzed using analysis of variance (ANOVA) while simple comparisons were analyzed using $t$-test with Bonferroni corrections applied where necessary. Normalized data was used for the fear conditioning, extinction training, and testing phases, while signal activity was examined in baseline groups using $t$-tests. All graphs plot means along with standard error. Statistical significance was assumed with a criterion of $P<0.05$ for all statistical tests.

\section{Competing interest statement}

D.K., N.M., and R.D.V have no conflict of interest concerning the findings presented in this manuscript.

\section{Acknowledgments}

The research in this report was funded by a pilot grant from the National Institutes of Health (NIH) (1P20GM103653) awarded to D.K. and a University of Delaware Research Foundation grant awarded to D.K. We would like to thank all of the undergraduate students who helped conduct research in this proposal.

\section{References}

Aizenberg M, Geffen MN. 2013. Bidirectional effects of aversive learning on perceptual acuity are mediated by the sensory cortex. Nat Neurosci 16: 994-996. doi:10.1038/nn.3443

American Psychiatric Association. 1994. Diagnostic and statistical manual of mental disorders. American Psychiatric Association, Washington, D.C.

Armario A, Escorihuela RM, Nadal R. 2008. Long-term neuroendocrine and behavioural effects of a single exposure to stress in adult animals. Neurosci Biobehav Rev 32: 1121-1135. doi:10.1016/j.neubiorev.2008.04 .003

Assareh N, Sarrami M, Carrive P, McNally GP. 2016. The organization of defensive behavior elicited by optogenetic excitation of rat lateral or ventrolateral periaqueductal gray. Behav Neurosci 130: 406-414. doi:10.1037/bne0000151

Badura-Brack A, McDermott TJ, Heinrichs-Graham E, Ryan TJ, Khanna MM, Pine DS, Bar-Haim Y, Wilson TW. 2018. Veterans with PTSD demonstrate amygdala hyperactivity while viewing threatening faces: a MEG study. Biol Psychol 132: 228-232. doi:10.1016/j.biopsycho.2018 .01 .005

Behbehani MM. 1995. Functional characteristics of the midbrain periaqueductal gray. Prog Neurobiol 46: 575-605. doi:10.1016/ 0301-0082(95)00009-K

Bouton ME, Westbrook RF, Corcoran KA, Maren S. 2006. Contextual and temporal modulation of extinction: behavioral and biological mechanisms. Biol Psychiatry 60: 352-360. doi:10.1016/j.biopsych.2005 .12 .015

Bowers ME, Ressler KJ. 2015. An overview of translationally informed treatments for posttraumatic stress disorder: animal models of Pavlovian fear conditioning to human clinical trials. Biol Psychiatry 78: E15-E27. doi:10.1016/j.biopsych.2015.06.008 
Bremner JD, Narayan M, Staib LH, Southwick SM, McGlashan T, Charney DS. 1999. Neural correlates of memories of childhood sexual abuse in women with and without posttraumatic stress disorder. Am J Psychiatry 156: 1787-1795.

Butler O, Herr K, Willmund G, Gallinat J, Zimmermann P, Kühn S. 2018. Neural correlates of response bias: larger hippocampal volume correlates with symptom aggravation in combat-related posttraumatic stress disorder. Psychiatry Res Neuroimaging 279: 1-7. doi:10.1016/j .pscychresns.2018.06.010

Carrive P, Leung P, Harris J, Paxinos G. 1997. Conditioned fear to context is associated with increased Fos expression in the caudal ventrolateral region of the midbrain periaqueductal gray. Neuroscience 78: 165-177. doi:10.1016/S0306-4522(97)83047-3

Deng H, Xiao X, Wang Z. 2016. Periaqueductal gray neuronal activities underlie different aspects of defensive behaviors. J Neurosci 36: 75807588. doi:10.1523/JNEUROSCI.4425-15.2016

Deslauriers J, Toth M, Der-Avakian A, Risbrough VB. 2018. Current status of animal models of PTSD: behavioral and biological phenotypes, and future challenges in improving translation. Biol Psychiatry 83: 895-907. doi: 10.1016/j.biopsych.2017.11.019

Do-Monte FH, Quiñones-Laracuente K, Quirk GJ. 2015. A temporal shift in the circuits mediating retrieval of fear memory. Nature 519: 460-463. doi:10.1038/nature14030

Eferl R, Wagner EF. 2003. AP-1: a double-edged sword in tumorigenesis. Nat Rev Cancer 3: 859-868. doi:10.1038/nrc1209

Furlong TM, Richardson R, McNally GP. 2016. Habituation and extinction of fear recruit overlapping forebrain structures. Neurobiol Learn Mem 128: $7-16$. doi:10.1016/j.nlm.2015.11.013

Ganon-Elazar E, Akirav I. 2013. Cannabinoids and traumatic stress modulation of contextual fear extinction and GR expression in the amygdala-hippocampal-prefrontal circuit. Psychoneuroendocrinology 38 : 1675-1687. doi:10.1016/j.psyneuen.2013.01.014

George SA, Knox D, Curtis A, Valentino R, Liberzon I. 2012. Altered locus coeruleus-norepinephrine function following single prolonged stress. Eur J Neurosci 37: 901-909. doi:10.1111/ejn.12095

George SA, Rodriguez-Santiago M, Riley J, Rodriguez E, Liberzon I. 2015. The effect of chronic phenytoin administration on single prolonged stress induced extinction retention deficits and glucocorticoid upregulation in the rat medial prefrontal cortex. Psychopharmacology (Berl) 232: 47-56. doi:10.1007/s00213-014-3635-x

Grosso A, Cambiaghi M, Renna A, Milano L, Roberto Merlo G, Sacco T, Sacchetti B. 2015. The higher order auditory cortex is involved in the assignment of affective value to sensory stimuli. Nat Commun 6: 8886 . doi:10.1038/ncomms9886

Gruene T, Flick K, Rendall S, Cho JH, Gray J, Shansky R. 2016. Activity-dependent structural plasticity after aversive experiences in amygdala and auditory cortex pyramidal neurons. Neuroscience 328: 157-164. doi:10.1016/j.neuroscience.2016.04.045

Hallock HL, Wang A, Griffin AL. 2016. Ventral midline thalamus is critical for hippocampal-prefrontal synchrony and spatial working memory. J Neurosci 36: 8372-8389. doi:10.1523/JNEUROSCI.0991-16.2016

Heinricher MM, Tavares I, Leith JL, Lumb BM. 2009. Descending control of nociception: specificity, recruitment and plasticity. Brain Res Rev 60: 214-225. doi:10.1016/j.brainresrev.2008.12.009

Imanaka A, Morinobu S, Toki S, Yamawaki S. 2006. Importance of early environment in the development of post-traumatic stress disorder-like behaviors. Behav Brain Res 173: 129-137. doi:10.1016/j.bbr.2006.06 .012

Iwamoto Y, Morinobu S, Takahashi T, Yamawaki S. 2007. Single prolonged stress increases contextual freezing and the expression of glycine transporter 1 and vesicle-associated membrane protein $2 \mathrm{mRNA}$ in the hippocampus of rats. Prog Neuropsychopharmacol Biol Psychiatry 31: 642651. doi:10.1016/j.pnpbp.2006.12.010

Johansen JP, Tarpley JW, LeDoux JE, Blair HT. 2010. Neural substrates for expectation-modulated fear learning in the amygdala and periaqueductal gray. Nat Neurosci 13: 979-986. doi:10.1038/nn.2594

Khan S, Liberzon I. 2004. Topiramate attenuates exaggerated acoustic startle in an animal model of PTSD. Psychopharmacology (Berl) 172: 225-229. doi:10.1007/s00213-003-1634-4

Kim EJ, Horovitz O, Pellman BA, Tan LM, Li Q, Richter-Levin G, Kim JJ. 2013. Dorsal periaqueductal gray-amygdala pathway conveys both innate and learned fear responses in rats. Proc Natl Acad Sci 110: 1479514800. doi:10.1073/pnas.1310845110

Kincheski GC, Mota-Ortiz SR, Pavesi E, Canteras NS, Carobrez AP. 2012. The dorsolateral periaqueductal gray and its role in mediating fear learning to life threatening events. PLoS One 7: e50361. doi:10.1371/journal .pone. 0050361

Knox D, Perrine SA, George SA, Galloway MP, Liberzon I. 2010. Single prolonged stress decreases glutamate, glutamine, and creatine concentrations in the rat medial prefrontal cortex. Neurosci Lett 480: 16-20. doi:10.1016/j.neulet.2010.05.052
Knox D, George SA, Fitzpatrick CJ, Rabinak CA, Maren S, Liberzon I. 2012a. Single prolonged stress disrupts retention of extinguished fear in rats. Learn Mem 19: 43-49. doi:10.1101/lm.024356.111

Knox D, Nault T, Henderson C, Liberzon I. 2012b. Glucocorticoid receptors and extinction retention deficits in the single prolonged stress model. Neuroscience 223: 163-173. doi:10.1016/j.neuroscience.2012.07.047

Knox D, Stanfield BR, Staib JM, David NP, Keller SM, DePietro T. 2016. Neural circuits via which single prolonged stress exposure leads to fear extinction retention deficits. Learn Mem 23: 689-698. doi:10.1101/lm .043141 .116

Knox D, Stanfield BR, Staib JM, David NP, DePietro T, Chamness M, Schneider EK, Keller SM, Lawless C. 2018. Using C-Jun to identify fear extinction learning-specific patterns of neural activity that are affected by single prolonged stress. Behav Brain Res 341: 189-197. doi:10.1016/j .bbr.2017.12.037

Kohda K, Harada K, Kato K, Hoshino A, Motohashi J, Yamaji T, Morinobu S, Matsuoka N, Kato N. 2007. Glucocorticoid receptor activation is involved in producing abnormal phenotypes of single-prolonged stress rats: a putative post-traumatic stress disorder model. Neuroscience 148: 22-33. doi:10.1016/j.neuroscience.2007.05.041

Koutsikou S, Watson TC, Crook JJ, Leith JL, Lawrenson CL, Apps R, Lumb BM. 2015. The periaqueductal gray orchestrates sensory and motor circuits at multiple levels of the neuraxis. J Neurosci 35: 1413214147. doi:10.1523/JNEUROSCI.0261-15.2015

Liberzon I, Sripada CS. 2008. The functional neuroanatomy of PTSD: a critical review. Prog Brain Res 167: 151-169. doi:10.1016/S0079-6123 (07)67011-3

Liberzon I, Krstov M, Young EA. 1997. Stress-restress: effects on ACTH and fast feedback. Psychoneuroendocrinology 22: 443-453. doi:10.1016/ S0306-4530(97)00044-9

Liberzon I, Abelson JL, Flagel SB, Raz J, Young EA. 1999a. Neuroendocrine and psychophysiologic responses in PTSD: a symptom provocation study. Neuropsychopharmacology 21: 40-50. doi:10.1016/S0893-133X (98)00128-6

Liberzon I, López JF, Flagel SB, Vázquez DM, Young EA. 1999b. Differential regulation of hippocampal glucocorticoid receptors mRNA and fast feedback: relevance to post-traumatic stress disorder. J Neuroendocrinol 11: $11-17$. doi: $10.1046 / j .1365-2826.1999 .00288 . x$

Madsen TM, Bolwig TG, Mikkelsen JD. 2006. Differential regulation of c-Fos and FosB in the rat brain after amygdala kindling. Cell Mol Neurobiol 26: 87-100. doi:10.1007/s10571-006-9202-1

Maisson DJ, Gemzik ZM, Griffin AL. 2018. Optogenetic suppression of the nucleus reuniens selectively impairs encoding during spatial working memory. Neurobiol Learn Mem 155: 78-85. doi:10.1016/j.nlm.2018.06 .010

Maren S. 2001. Neurobiology of Pavlovian fear conditioning. Аnnu Rev Neurosci 24: 897-931. doi:10.1146/annurev.neuro.24.1.897

Maren S, Phan KL, Liberzon I. 2013. The contextual brain: implications for fear conditioning, extinction and psychopathology. Nat Rev Neurosci 14: 417-428. doi:10.1038/nrn3492

McNally GP, Pigg M, Weidemann G. 2004. Opioid receptors in the midbrain periaqueductal gray regulate extinction of Pavlovian fear conditioning I Neurosci 24: 6912-6919. doi:10.1523/JNEUROSCI.1828-04.2004

Noble LJ, Gonzalez IJ, Meruva VB, Callahan KA, Belfort BD, Ramanathan KR, Meyers E, Kilgard MP, Rennaker RL, McIntyre CK. 2017. Effects of vagus nerve stimulation on extinction of conditioned fear and post-traumatic stress disorder symptoms in rats. Transl Psychiatry 7: e1217. doi:10.1038/tp.2017.191

Orsini CA, Maren S. 2012. Neural and cellular mechanisms of fear and extinction memory formation. Neurosci Biobehav Rev 36: 1773-1802. doi:10.1016/j.neubiorev.2011.12.014

Paré D, Quirk GJ, Ledoux JE. 2004. New vistas on amygdala networks in conditioned fear. I Neurophysiol 92: 1-9. doi:10.1152/jn.00153.2004

Penzo MA, Robert V, Tucciarone J, De Bundel D, Wang M, Van Aelst L, Darvas M, Parada LF, Palmiter RD, He M, et al. 2015. The paraventricular thalamus controls a central amygdala fear circuit. Nature 519: 455-459. doi:10.1038/nature13978

Ramanathan KR, Ressler RL, Jin J, Maren S. 2018. Nucleus reuniens is required for encoding and retrieving precise, hippocampal-dependent contextual fear memories in rats. J Neurosci 38: 9925-9933. doi:10.1523/ JNEUROSCI.1429-18.2018

Rea K, Roche M, Finn DP. 2011. Modulation of conditioned fear, fear-conditioned analgesia, and brain regional c-Fos expression following administration of muscimol into the rat basolateral amygdala. J Pain 12: 712-721. doi:10.1016/j.jpain.2010.12.010

Rothbaum BO, Davis M. 2003. Applying learning principles to the treatment of post-trauma reactions. Ann N Y Acad Sci 1008: 112-121. doi:10.1196/ annals.1301.012

Schneider MD, McLellan WR, Black FM, Parker TG. 1992. Growth factors, growth factor response elements, and the cardiac phenotype. Basic Res Cardiol 87: 33-48. doi:10.1007/978-3-642-72477-0_4 
Shin LM, Orr SP, Carson MA, Rauch SL, Macklin ML, Lasko NB, Peters PM, Metzger LJ, Dougherty DD, Cannistraro PA, et al. 2004. Regional cerebral blood flow in the amygdala and medial prefrontal cortex during traumatic imagery in male and female Vietnam veterans with PTSD. Arch Gen Psychiatry 61: 168-176. doi:10.1001/ archpsyc.61.2.168

Teather LA, Packard MG, Smith DE, Ellis-Behnke RG, Bazan NG. 2005. Differential induction of c-Jun and Fos-like proteins in rat hippocampus and dorsal striatum after training in two water maze tasks. Neurobiol Learn Mem 84: 75-84. doi:10.1016/j.nlm.2005.03.006

Vanderheyden WM, George SA, Urpa L, Kehoe M, Liberzon I, Poe GR. 2015. Sleep alterations following exposure to stress predict fear-associated memory impairments in a rodent model of PTSD. Exp Brain Res 233: 2335-2346. doi:10.1007/s00221-015-4302-0

van Zuiden M, Geuze E, Willemen HL, Vermetten E, Maas M, Heijnen CJ, Kavelaars A. 2011. Pre-existing high glucocorticoid receptor number predicting development of posttraumatic stress symptoms after military deployment. Am J Psychiatry 168: 89-96. doi:10.1176/appi.ajp.2010 .10050706

van Zuiden M, Kavelaars A, Geuze E, Olff M, Heijnen CJ. 2013. Predicting PTSD: pre-existing vulnerabilities in glucocorticoid-signaling and implications for preventive interventions. Brain Behav Immun 30: 12-21. doi:10.1016/j.bbi.2012.08.015

Wang HT, Han F, Gao JL, Shi YX. 2010. Increased phosphorylation of extracellular signal-regulated kinase in the medial prefrontal cortex of the single-prolonged stress rats. Cell Mol Neurobiol 30: 437-444. doi:10.1007/s10571-009-9468-1

Watson TC, Cerminara NL, Lumb BM, Apps R. 2016. Neural correlates of fear in the periaqueductal gray. J Neurosci 36: 12707-12719. doi:10.1523/ JNEUROSCI.1100-16.2016
Weinberger NM. 2011. The medial geniculate, not the amygdala, as the root of auditory fear conditioning. Hear Res 274: 61-74. doi:10.1016/j.heares .2010 .03 .093

Windak R, Muller J, Felley A, Akhmedov A, Wagner EF, Pedrazzini T, Sumara G, Ricci R. 2013. The AP-1 transcription factor c-Jun prevents stress-imposed maladaptive remodeling of the heart. PLoS One 8: e73294. doi:10.1371/journal.pone.0073294

Yamamoto S, Morinobu S, Fuchikami M, Kurata A, Kozuru T, Yamawaki S. 2008. Effects of single prolonged stress and D-cycloserine on contextual fear extinction and hippocampal NMDA receptor expression in a rat model of PTSD. Neuropsychopharmacology 33: 2108-2116. doi:10.1038/ sj.npp.1301605

Yehuda R, Teicher MH, Trestman RL, Levengood RA, Siever LJ. 1996. Cortisol regulation in posttraumatic stress disorder and major depression: a chronobiological analysis. Biol Psychiatry 40: 79-88. doi:10.1016/0006-3223(95)00451-3

Yehuda R, Yang RK, Buchsbaum MS, Golier JA. 2006. Alterations in cortisol negative feedback inhibition as examined using the ACTH response to cortisol administration in PTSD. Psychoneuroendocrinology 31: 447-451. doi:10.1016/j.psyneuen.2005.10.007

Zhang J, Tan L, Ren Y, Liang J, Lin R, Feng Q, Zhou J, Hu F, Ren J, Wei C, et al. 2016. Presynaptic excitation via GABAB receptors in habenula cholinergic neurons regulates fear memory expression. Cell 166: 716728. doi:10.1016/j.cell.2016.06.026

Received July 14, 2019; accepted in revised form July 20, 2019. 


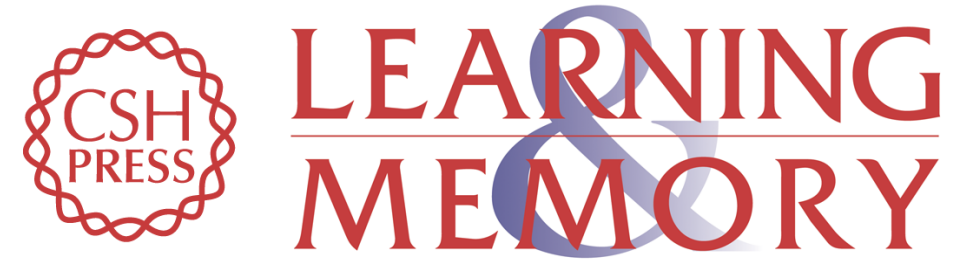

\section{Single prolonged stress alters neural activation in the periacqueductal gray and midline thalamic nuclei during emotional learning and memory}

Rebecca Della Valle, Negin Mohammadmirzaei and Dayan Knox

Learn. Mem. 2019, 26:

Access the most recent version at doi:10.1101/lm.050310.119

References This article cites 65 articles, 9 of which can be accessed free at: http://learnmem.cshlp.org/content/26/10/403.full.html\#ref-list-1

Creative This article is distributed exclusively by Cold Spring Harbor Laboratory Press for the Commons first 12 months after the full-issue publication date (see

License http://learnmem.cshlp.org/site/misc/terms.xhtml). After 12 months, it is available under a Creative Commons License (Attribution-NonCommercial 4.0 International), as described at http://creativecommons.org/licenses/by-nc/4.0/.

Email Alerting Receive free email alerts when new articles cite this article - sign up in the box at the Service top right corner of the article or click here. 